\title{
Como seria o financiamento de um Sistema Nacional de Educação na perspectiva do Manifesto dos Pioneiros da Educação Nova ${ }^{1}$
}

\author{
How about the financing of a Education National System in the \\ perspective of the Pioneers of the New Education Manifest
}

\section{Paulo Sena Martins ${ }^{2}$ José Marcelino de Rezende Pinto ${ }^{3}$}

\section{Resumo:}

O artigo analisa as posições apresentadas no Manifesto dos Pioneiros da Educação Nova (1932), com vistas a avaliar os elementos indicativos de um sistema nacional de educação e as bases para o seu financiamento, sob aquelas perspectivas. Para tanto, o texto percorre o contexto de produção e publicação do Manifesto, os signatários, e a analisa o documento propriamente dito. Ao final, produz um balanço preliminar e indica análises para além do próprio Manifesto, buscando cotejar os impactos na legislação e o aprofundamento das propostas de financiamento elaboradas por Anísio Teixeira.

Palavras-chave: Manifesto dos Pioneiros; Financiamento da Educação; Sistema Nacional de Educação.

\section{Abstract:}

The article analyzes the positions stated in the Brazilian Manifesto of the Pioneers of the New Education (1932), in order to evaluate the indicative elements of a Brazilian National Education System and the bases for education funding under those perspectives. To this end, the article shows the context of the production and publication of the Manifesto, the signatories, and analyzes the document itself. At the end, the work produces a preliminary balance and indicates analyses beyond the Manifesto itself, seeking to collate the impact on legislation and advance the financing proposals made by Anisio Teixeira.

Keywords: Manifesto of the Pioneers; Financing of Education; National Education System.

10 s direitos autorais deste artigo estão cedidos ao Ministério da Educação - MEC, que gentilmente liberou-os para publicação neste periódico. Em breve, o leitor poderá acessar também este artigo em livro especial organizado pelo MEC sobre os Pioneiros da Educação Brasileira.

2 Doutor em Educação (UnB). Consultor legislativo na Câmara dos Deputados. E-mail: paulo.martins@camara.gov.br.

3 Doutor em Educação (UNICAMP). Professor e pesquisador da FFCLRP-USP. Presidente da Associação Nacional de Pesquisa em Financiamento da Educação - FINEDUCA. E-mail: jmrpinto@ffclrp.usp.br. 
Esta ideia foi sugerida no Brasil dezenas e dezenas de vezes e nunca conseguiu vencer. Uma daquelas permanentes brasileiras, o espírito fazendário, sempre impediu a criação de fundos autônomos para a educação [...]

0 direito à educação passou a ser um dos direitos constitucionais do cidadão brasileiro.

Para efetivação desse direito, de natureza constitucional, o Estado assume plena responsabilidade, nos termos de dispositivos expressos na Constituição.

Essa responsabilidade, em virtude do caráter federativo do Estado, no Brasil, é solidária, obrigando simultânea e completamente as três esferas de Poder Público: a União, os Estados e os Municípios.

Tal obrigação solidária, a ser exercida conjuntamente e de modo mutuamente complementar, torna indispensável um mínimo de ação coordenada e uniforme em que, acima de tudo, se fixem as responsabilidades de financiamento do esforço comum de educação de todos os brasileiros.

Anísio Teixeira (Educação é um Direito, 1968)

\section{I- Contexto do Manifesto}

Nos anos subsequentes à proclamação da República, o país passava por uma série de transformações, com a diversificação da estrutura social. Avançavam os processos iniciais de industrialização e urbanizaçãotransformações, no entanto, que não se deram de forma homogênea entre as regiões e os estados. Em alguns, surgiam pequenas propriedades no campo, a partir da inserção dos imigrantes na sociedade. Crescia o operariado industrial. Expandia-se a classe média urbana que ganhava visibilidade na cena política e almejava converter a República oligárquica em República liberal. Para tanto, depositava esperanças na educação popular, no voto secreto e na criação da justiça eleitoral (FAUSTO, 1994).

Os intelectuais, alguns desiludidos com os rumos da República passaram a defender a "republicanização" da República (NAGLE, 1974; GHIRALDELLI JR, 2006). Para Romanelli, "as classes médias em ascensão reivindicavam o ensino médio e as camadas populares o ensino primário" (Romanelli, 2003, p.143). Inicia-se um ciclo de reformas da educação em alguns estados.

Quadro 1: Reformas educacionais nos estados na década de 1920 do século XX

\begin{tabular}{|c|c|c|}
\hline Estado & Ano de início & Liderança \\
\hline São Paulo & 1920 & Sampaio Dória \\
\hline Ceará & 1922 & Lourenço Filho \\
\hline Paraná & 1923 & Lysimaco Ferreira da Costa e Prieto Martinez \\
\hline Rio Grande do Norte & 1924 & José Augusto \\
\hline Bahia & 1925 & Anísio Teixeira \\
\hline Minas Gerais & 1927 & Francisco Campos e Mário Casasanta \\
\hline Distrito Federal (Rio de Janeiro) & 1927 & Fernando de Azevedo \\
\hline Pernambuco & 1929 & Carneiro Leão \\
\hline
\end{tabular}

A partir de 1922 eclodiam as revoltas tenentistas. Realizava-se a Semana de Arte Moderna. O país ingressava na era da radiodifusão com a inauguração da Rádio Sociedade do Rio de Janeiro, por Roquete Pinto, que anos depois seria um dos signatários do Manifesto. Era fundado o partido comunista. É neste contexto que se cria o ambiente denominado por Nagle (1974) de entusiasmo pela educação. Em 1924 é fundada a Associação Brasileira de Educação - ABE.

Nunes sintetiza: 
Enquanto tenentes, artistas e escritores modernistas propugnavam a revolução política e estética, os educadores reformistas fundavam, numa sala da Escola Politécnica do Rio, a Associação Brasileira de Educação (ABE), defendendo a regeneração dos costumes políticos, a organização e o controle da opinião pública (NUNES, 1999, p.35).

A ABE, continua a autora, apresentava-se ao Estado como órgão de opinião das "classes cultas". A entidade reunia dois blocos: o grupo liberal-democrata (entre os quais Fernando de Azevedo, Anísio Teixeira, Lourenço Filho, Paschoal Leme), que posteriormente seria o responsável pelo Manifesto e o grupo católico (Hélder Câmara, Alceu Amoroso Lima, Jônatas Serrano, entre outros). A unidade deste grupo heterogêneo era mantida pela campanha cívico-educacional conduzida pela ABE a partir de ações que visavam a organização da nacionalidade por meio da organização da cultura (CARVALHO, 1999). Mas havia diferenças.

Disputavam duas visões, no âmbito da Associação Brasileira de Educação: de um lado o grupo ligado à Igreja Católica que via a religião como base da nacionalidade e a importância da tutela da Igreja sobre o ensino público. De outro, representado pelo grupo que se articulava em torno de Fernando de Azevedo, cuja perspectiva era de uma educação pública, estatal e obrigatória e com a coedução, com ensino igual para ambos os sexos. A obrigatoriedade deveria se estender progressivamente até uma idade conciliável com o trabalho produtor, isto é, até aos 18 anos.

Além da questão da diferença de concepções, Carvalho destaca outra dimensão da controvérsia - uma disputa de poder:

A criação do Ministério da Educação e Saúde inaugura espaços de poder de importância estratégica na configuração e no controle, técnico e doutrinário, do aparelho escolar. Com isso o consenso em torno da causa educacional transmuda-se em disputa pela implementação de programas político-pedagógicos concorrentes (CARVALH0, 1999, p.17).

Como acentua Xavier (2002, p.55), os católicos interpretavam a questão social como uma questão espiritual a ser solucionada com base em uma reforma moral da sociedade, enquanto os pioneiros propunham a intervenção racional no sistema educacional ampliando-a ao âmbito de uma reforma social. Esses grupos conviveram até 1931, quando se deu a cisão, por ocasião da IV Conferência Brasileira de Educação, no Rio de Janeiro.

O país já vivia sob nova ordem, vitoriosa a revolução de 30 - que apresentava um momento ímpar para influenciar nas políticas. Anísio Teixeira, em carta endereçada a Fernando de Azevedo, comenta sobre o clima de instabilidade que o país vivia: "Corria-se o risco de ver-se a história da Revolução brasileira perder-se como a história de uma revolução que se perdeu" (citada por VIANA FILHO, 1990, p. 56 apud PAGNI, 2000, p. 65).

\section{A IV Conferência tinha como título "As grandes diretrizes da educação popular"}

Conforme assinala Carvalho (1999), tudo indica que os organizadores da Conferência - do grupo católico, que controlava a ABE desde 1929 - "sintonizados com o Ministério da Educação, contavam referendar, na sua assembleia de encerramento, uma política educacional que perpetuava a dualidade do sistema escolar e Ihe imprimia orientação religiosa".

O governo provisório de Vargas reconhecera não só a constituição de um domínio setorial (desde a criação do Ministério da Educação e Saúde Pública, em 1931), mas também os atores relevantes para a construção da política setorial da educação.

A criação do ministério, compromisso de campanha de Vargas, alimentou a expectativa de que os renovadores fossem guindados à sua condução. Em artigo de 25 de dezembro de 1930, no Diário de Notícias, escrevia a poetisa Cecília Meireles, que seria signatária do manifesto:

A notícia, em circulação, de que o próximo governo criará o ministério da educação pública e, à sua frente colocará 0 atual diretor de Instrução do Distrito Federal (Fernando de Azevedo), é de imenso valor para quem se interessa pelo problema educacional (MEIRELES, 2001, p.110) 
Entretanto, foi indicado como titular Francisco Campos, um educador de forte envolvimento com a área e grande cacife político (PINTO, 2000). Em tese, o ministro era afinado com as ideias pedagógicas dos renovadores - liderara, ao lado de Mário Casasanta, a reforma educacional em Minas Gerais. Contudo, uma vez no governo, implementou um política que destoava dos princípios dos renovadores. Iniciou reformas em 1931, entre as quais o restabelecimento do ensino religioso (facultativo) nas escolas primárias e secundárias, ministrado por professores de instrução religiosa designados pelas autoridades do culto a que se referisse o ensino ministrado.

Vargas acenava à igreja católica, para assegurar seu apoio ao governo, em resposta ao contundente recado do cardeal D. Leme, que mobilizou os clérigos e fiéis, e perante cinquenta arcebispos declarou que "ou o estado reconhece o Deus do povo, ou o povo não reconhecerá o estado" (CUNHA,1981, p.84).

Cecília Meireles (2001, p.162) escrevia, em tom que revela o grau de indignação com o ministro e de polarização do momento, entre os dois blocos da ABE:

Mas o sr. Francisco Campos parece que resolveu dar cada dia uma prova mais convincente de que não entende mesmo nada, absolutamente, de pedagogia. Que a sua pedagogia é uma pedagogia de ministro, isto é, politicagem...

E assim, antes que aqui tivéssemos estudado o caso das reformas, deixou desabar, do seu ministério para as mãos do sr. Getúlio Vargas, um decreto tornando obrigatório o ensino religioso nas escolas.

Estiveram presentes na abertura da IV Conferência da ABE, o chefe do governo provisório, Getúlio Vargas e o ministro Francisco Campos. Para Saviani (2007), o governo buscava na ABE a legitimação de sua política educacional enquanto o grupo católico que a controlava (e já havia sido contemplado com o decreto acerca do ensino religioso) buscava espaços no aparelho de Estado para consolidar sua hegemonia sobre o campo educacional. O próprio ministro convocara, por carta, as delegações estaduais (XAVIER, 2002).

Campos pediu à assembleia as "grandes linhas" para a educação nacional (FREITAS, 2005), a apresentação de um 'conceito de educação' (CUNHA, 2003), ao se pronunciar:

Estou, porém, inclinado a crer que toda conferência de educação deveria começar seus trabalhos assentando uma preliminar: Que é que entendemos por educação, ou de que educação vamos discutir os processos, os métodos ou as aplicações? Tudo o que se segue depende da postulação inicial e as discussões ganhariam em clareza, porque os termos nelas usados teriam uma significação definida e única (apud CUNHA, 2003, p.38).

Vargas exortou os educadores presentes a definir as bases da política educacional que deveria guiar as ações do governo (SAVIANI, 2007; CUNHA, 2003).

Assim se pronunciou:

Estais agora aqui congregados, sois todos profissionais e técnicos. Pois bem: estudai com dedicação; analisai com interesse todos os problemas da educação; procurai encontrar a fórmula mais feliz da colaboração do Governo Federal com os dos Estados - que tereis na atual administração todo o amparo ao vosso esforço. Buscai por todos os meios a fórmula mais feliz que venha a estabelecer, em todo o nosso grande território, a unidade da educação nacional, porque tereis, assim, contribuído com esforço maior do que se poderia avaliar para tornar mais fortes, mais vivos e mais duradouros os vínculos da solidariedade nacional (grifos nossos)

Aproveitando-se dos discursos das autoridades, Nóbrega da Cunha manobrou habilmente para que, dada as limitações de tempo da plenária, que incumbisse um de seus grupos de redigir um documento que fosse objeto de discussão na $\vee$ Conferência. Afirmou que o grupo por ele representado se manifestaria por intermédio de Fernando de Azevedo, que não estava presente Conferencia, mas esteve em contato constante com Nóbrega da Cunha e aceitou por telefone a incumbência de redigir o documento entre janeiro e fevereiro de 1932 e submetê-lo à apreciação do 'nosso grupo' (PAGNI, 2000, p 71).

Com isso evitou-se o embate direto na IV Conferência - na qual o peso dos 'conservadores' era grande, e ganhou-se tempo para a articulação dos pioneiros e criação de um fato consumado via publicação do documento na grande imprensa. 
O lançamento de seu manifesto, em março de 1932, teve como efeito a retirada do grupo católico da ABE, ato formalizado em reunião de seu conselho diretor, pouco antes da V Conferência. Assim, em 1933 o grupo católico fundou a Confederação Católica Brasileira de Educação (SAVIANI, 2007).

Para Freitas (2005), o Manifesto surgiu quando o grupo dos pioneiros quis explicitamente se diferenciar do segmento católico e defender que o Estado se responsabilizaria pela escola pública e atenderia ao direito básico de cada um - o "direito biológico" à educação. O Manifesto dava visibilidade à defesa e sistematização de um sistema único de ensino, público, leigo e gratuito (CARVALHO, 1999).

\section{II- Os signatários (homens e mulheres) do Manifesto}

O grupo dos 26 signatários do Manifesto era heterogêneo (SAVIANI, 2007; GHIRALDELLI JR, 2006) e abrangia liberais progressistas (Anísio Teixeira, Fernando de Azevedo), socialistas com simpatias pelo anarquismo (Roldão Lopes de Barros), signatários que posteriormente se tornaram marxistas (Hermes Lima e Paschoal Leme), tenentistas (Edgard Sussekind). Havia personalidades ligadas às elites paulistas (Júlio de Mesquita Filho, proprietário do jornal O Estado de São Paulo), proprietária de escola privada (Armanda Álvaro Alberto) intelectuais que, para Ghiraldelli Jr (2006), no decorrer da década de 1930 assumiriam posições teóricas ligeiramente comprometidas com as reflexões bastante conservadoras (Raul Briquet), além de intelectuais progressistas como a poetisa Cecília Meireles, que dirigia a "página de educação" no Diário de Notícias e o jornalista Nóbrega da Cunha.

Xavier (2002) ressalta que vários deles tinham participação ativa em associações de educadores profissionais de diferentes níveis e em associações científico-acadêmicas nacionais e internacionais e que todos já haviam publicado livros sobre temas variados, sobretudo acerca de temas educacionais. Registra, ainda que: "Eram profissionais de formações diversas - médicos, advogados, jornalistas, professores - provenientes de diversos estados do país, especialmente do Rio de Janeiro, São Paulo, Bahia e Minas Gerais" (XAVIER, 2002, p.26).

Para Ghiraldelli Jr (2006), todos os signatários, ao longo das décadas de 1920 e 1930 contribuíram para o crescimento da literatura pedagógica e difusão dos idéias da escola nova, mas a marca do movimento renovador acompanhou três dos signatários: Anísio Teixeira, Fernando de Azevedo e Lourenço Filho - homens de pensamento, mas também de ação, tendo encabeçado várias reformas educacionais de peso.

\section{III- Análise do documento: a Escola Nova e o financiamento}

O Manifesto foi, conforme anunciado por Cunha na Conferência, redigido por Fernando de Azevedo. Nas ideias defendidas no texto fica evidente a influência de Anísio Teixeira ${ }^{4}$, revelada na estrutura do manifesto, que continha, além de princípios sociológicos caros a Fernando de Azevedo, princípios filosóficos próximos à visão de Anísio Teixeira. Estes deveriam nortear a educação e um "plano de educação embutido"; bem coerente até com a 'demanda' de Vargas.

Para Freitas (2005), o Manifesto é um documento de interpelação e exigência pública para que estado e governo assumissem uma nova responsabilidade sobre a nação.

O documento reafirma a crença no conhecimento científico, para demarcar o embate com os pensadores do campo católico. Além disso, é permeado pelo contraste dos termos de várias dicotomias, que explicitam o confronto de posições (CARVALHO, 1999) - escola única/escola dual, ensino público/ensino particular, ensino

4 A amizade entre Fernando de Azevedo e Anísio Teixeira havia começado em uma tarde de junho de 1929, quando este, que acabara de retornar dos EUA onde havia se graduado em Ciências da Educação na Columbia Úniversity, chega ao gabinete daquele, então Diretor da Instrução Pública do DF, com carta de Monteiro Lobato, que assim se exprimia: "Fernando ao receberes esta, pára! Bota pra fora qualquer senador que esteja te aporrinhando. Solta o pessoal da sala e atende 0 apresentado, pois ele é nosso grande Anísio Teixeira, a inteligência mais brilhante e o maior coração que já encontrei nestes últimos anos de minha vida. O Anísio viu, sentiu e compreendeu a América e aí te dirá o que realmente significa esse fenômeno novo no mundo" (VIDAL, 2000, p.161). 
leigo/ensino religioso e a interpretação que os (autodenominados) renovadores davam a este confronto: velho/ novo, passado/presente, tradicional/moderno (XAVIER, 2002).

O ponto de partida é o diagnóstico de uma realidade educacional "sem unidade de plano e sem espírito de continuidade" 5 , enfim "tudo fragmentário e desarticulado".

Assim, o "aparelho escolar" apresenta-se caracterizado mais pela "inorganização" do que pela "desorganização". Para reverter esse quadro de coisas é fundamental a determinação dos "fins de educação (aspecto filosófico e social) e da aplicação (aspecto técnico) dos métodos científicos aos problemas de educação".

Em seguida, realçam-se as mudanças profundas no campo educacional que já aconteciam em vários países: De fato, porque os nossos métodos de educação haviam de continuar a ser tão prodigiosamente rotineiros, enquanto no México, no Uruguai, na Argentina e no Chile, para só falar na América espanhola, já se operavam transformações profundas no aparelho educacional, reorganizado em novas bases e em ordem a finalidades lucidamente descortinadas?

E chega-se aos exemplos de reformas ocorridas no Brasil, não por acaso, capitaneadas pelos primeiros signatários do documento: Não tardaram a surgir no Distrito Federal e em três ou quatro Estados as reformas e, com elas, as realizações, com espírito científico, e inspiradas por um ideal que, modelado à imagem da vida, já Ihe refletia a complexidade.

O manifesto defendia a transferência do terreno administrativo para os planos político-sociais para a solução dos problemas escolares.

Vejamos então, no que se refere às implicações para o financiamento da educação, os principais pontos de uma proposta de mudança educativa baseada na "força das ideias" e na "irradiação dos fatos", como aponta o documento.

Algumas das ideias defendidas no manifesto foram amadurecendo ao longo da década de 1920. A Conferência Interestadual do Ensino Primário, realizada no Rio de Janeiro em 1921, por convocação do Ministério da Justiça (ainda não fora criado o Ministério da Educação) defende a cooperação entre União e Estados e a vinculação de percentuais da receita às despesas com educação (10\%). As reformas estaduais lideradas pelos renovadores incluíam fundos de educação.

Em 1925, no plano federal, a Reforma João Luiz Alves estabelecia o concurso da União para a difusão do ensino primário (Decreto n 16.782/1925), previa acordos do governo da União com os dos Estados, nos quais se estabeleceu - precedente ao disposto na atual Lei do Piso Salarial do Magistério, no contexto do Fundeb - a obrigação da União de pagar diretamente os vencimentos dos professores primários das escolas rurais, até o máximo de 2:400\$ anuais, e os Estados obrigavam-se a aplicar, no mínimo, 10\% das suas receitas na instrução primária e normal (Decreto n 16.782/1925, art. 25).

Apesar de, por um lado, mostrar a disposição do poder central em participar da luta contra o analfabetismo, até então entregue aos Estados, tratou-se, contudo, de uma reforma caracterizada pela centralização autoritária, que prosseguiria nas reformas de Campos e no Estado Novo (CUNHA, 1981). Cooperação e reserva de recursos já circulavam como ideias, antes do Manifesto. Por exemplo, a mensagem do chefe do governo provisório da vitoriosa Revolução de 1930, Getúlio Vargas, apresentada à Assembleia Constituinte: a) mencionava o "espírito de cooperação", a partir do qual deveriam ser congregados os esforços da União, dos Estados e dos Municípios; b) defendia que os entes federativos dedicassem "uma percentagem fixa de seus orçamentos para prover as despesas da instrução, elevada ao máximo". Assinalava que o decreto destinado a regular os poderes e atribuições dos Interventores determinava que os Estados empregassem 10\%, no mínimo, das respectivas rendas na instrução primária e estabelecia a faculdade de exigir até 15\% das receitas municipais para aplicação nos serviços de segurança, saúde e instrução públicas, quando por eles exclusivamente atendidos.

5 Os textos entre aspas a seguir foram extraídos do Manifesto. 
Em seu Manifesto (AZEVEDO, 1932), os pioneiros, em primeiro lugar, realçam a educação como uma das "funções essenciais e primordiais do Estado".

Assentado o princípio do direito biológico de cada indivíduo à sua educação integral, cabe evidentemente ao Estado a organização dos meios de o tornar efetivo, por um plano geral de educação, de estrutura orgânica, que torne a escola acessível, em todos os seus graus, aos cidadãos a quem a estrutura social do país mantém em condições de inferioridade econômica para obter o máximo de desenvolvimento de acordo com as suas aptidões vitais.

O documento aponta então para uma "escola comum ou única", assegurada a todos, independentemente da classe social a que pertençam. Não se defende o monopólio estatal da educação, mas, até onde se pode depreender do documento, apenas porque o "Estado, pela sua situação financeira não está ainda em condições de assumir a sua responsabilidade exclusiva". Assume-se como diretriz "uma escola oficial, única, em que todas as crianças, de 7 a 15 anos, todas ao menos que nessa idade, sejam confiadas pelos pais à escola pública, tenham uma educação comum, igual para todos".

Outro princípio com forte impacto no financiamento da educação refere-se à gratuidade do ensino nas instituições oficiais, em todos os níveis, como única forma de tornar a educação "acessível não a uma minoria, por um privilégio econômico, mas a todos os cidadãos que tenham vontade e estejam em condições de recebê-la". Aponta-se também para a progressiva extensão da obrigatoriedade "até os 18 anos", embora, no país, o ensino obrigatório, "por falta de escolas, ainda não passou do papel, nem em relação ao ensino primário". E ressalta, com lucidez que "não se pode tornar o ensino obrigatório, sem torná-lo gratuito".

Propugnam que a educação é uma função essencialmente pública e reivindicam autonomia e meios materiais para realizá-la (AZEVEDO, 1958, p.66 e 69).

Vejamos agora aspectos mais diretamente relacionados à gestão e ao financiamento e que são tratados na alínea "c" do item "A função educacional" do Manifesto.

Surge a ideia da criação de um fundo, como forma de dotar a educação de autonomia que afaste as "influências e intervenções estranhas que conseguiram sujeitá-la a seus ideais secundários e interesses subalternos". Para tanto, propõe-se "uma ampla autonomia técnica, administrativa e econômica", ficando a responsabilidade pela "direção e administração da função educacional" em mãos de "técnicos e educadores", assegurando-se "os meios materiais para poderem realizá-la". Assim, prossegue o Manifesto:

Mas do direito de cada indivíduo à sua educação integral, decorre logicamente para o estado que o reconhece e o proclama, 0 dever de considerar a educação, na variedade de seus graus e manifestações, como uma função social e eminentemente pública, que ele é chamado a realizar, com a cooperação de todas as instituições sociais.

[...] Esses meios, porém, não podem reduzir-se às verbas que, nos orçamentos, são consignadas a esse serviço público e, por isto, sujeitas às crises dos erários do Estado ou às oscilações do interesse dos governos pela educação. A autonomia econômica não se poderá realizar, a não ser pela instituição de um "fundo especial ou escolar", que, constituído de patrimônios, impostos e rendas próprias, seja administrado e aplicado exclusivamente no desenvolvimento da obra educacional, pelos próprios órgãos do ensino, incumbidos de sua direção (grifos nossos).

Como se pode concluir nesta parte do documento encontra-se a fórmula "autonomia + recursos vinculados" que vai permear a política de financiamento da educação brasileira daí pra frente, inaugurando-se com a introdução da vinculação de impostos para a manutenção e desenvolvimento do ensino e chegando hoje à política de fundos e ao princípio do art. $69, \S 5^{\circ}$ da LDB, que determina que os recursos vinculados devem ser repassados pelos órgãos arrecadadores ao órgão responsável pela educação de dez em dez dias.

O programa dos pioneiros expresso no Manifesto não olvidava a questão federativa (AZEVEDO, 1958, p.69): A organização da educação brasileira unitária sobre a base e os princípios do Estado, no espírito da verdadeira comunidade popular e no cuidado da unidade nacional, não implica um centralismo estéril e odioso, ao qual se opõem as condições geográficas do país e a necessidade de adaptação crescente da escola aos interesses e às exigências regionais. Unidade não significa uniformidade. A unidade pressupõe multiplicidade. Por menos que pareça, à primeira vista, não é, pois, na centralização, 
mas na aplicação da doutrina federativa (grifo nosso) e descentralizadora, que teremos de buscar o meio de levar a cabo, em toda a República, uma obra metódica e coordenada, de acordo com um plano comum, de completa eficiência, tanto em intensidade como em extensão (grifo dos autores).

E, como se daria esta organização "federativa e descentralizadora"? Segundo o documento, seria da União a competência pela educação "em todos os seus graus" na capital, cabendo aos Estados a responsabilidade pela educação em seus territórios. Curiosamente, o texto nada fala sobre os municípios, sendo que, nessa época muitos deles já eram responsáveis por parcela significativa do então ensino primário. Caberia ainda ao governo central, por meio do Ministério da Educação "vigiar" sobre a obediência aos princípios gerais fixados na "na carta constitucional e em leis ordinárias, socorrendo onde haja deficiências de meios". Encontra-se aqui também, uma primeira formulação do princípio da função supletiva da União, consagrado hoje no art. 211 da CF. Prossegue o texto ressaltando o papel da União de responsável por assegurar "a unidade educativa", sob o risco de "perecer como nacionalidade", assegurando-se um "regime livre de intercâmbio, solidariedade e cooperação que, levando os Estados a evitar todo desperdício nas suas despesas escolares a fim de produzir os maiores resultados com as menores despesas, abrirá margem a uma sucessão ininterrupta de esforços fecundos em criações e iniciativas".

De alguma maneira, era uma das respostas à "fórmula mais feliz" requerida pelo chefe do governo. Como mencionado, Vargas dirigiu-se à IV Conferência Nacional de Educação, promovida pela ABE (1931), para que definisse os princípios e apresentasse a "fórmula mais feliz", expressão que tem sido interpretada no sentido mais amplo vinculado à expressão de uma política educacional da Revolução de 30 (AZEVEDO, 1976, p.174). Entretanto, destacamos que a expressão "a fórmula mais feliz" é utilizada duas vezes no discurso de Vargas uma remetendo ao estabelecimento da unidade da educação nacional e outra que se referia expressamente à dimensão federativa: a "fórmula mais feliz" para a "colaboração do governo federal com os estados" e à "unidade da educação nacional" (CUNHA, 2003).

Há, ainda alguns itens que repercutem no financiamento:

a) Educação superior - item "c":

Defende a "educação superior ou universitária, a partir dos 18 anos, inteiramente gratuita" visando à "formação profissional e técnica, no seu máximo desenvolvimento, como à formação de pesquisadores, em todos os ramos do conhecimento humano". E já lança o tripé: ensino, pesquisa e extensão.

b) Professores - item "a":

Propõe a unidade de formação e de remuneração dos professores :

A tradição das hierarquias docentes, baseadas na diferenciação dos graus de ensino, e que a linguagem fixou em denominações diferentes (mestre, professor e catedrático), é inteiramente contrária ao princípio da unidade da função educacional, que, aplicado às funções docentes, importa na incorporação dos estudos do magistério às universidades, e, portanto, na libertação espiritual e econômica do professor, mediante uma formação e remuneração equivalentes que Ihe permitam manter, com a eficiência no trabalho, a dignidade e o prestígio indispensáveis aos educadores.

Como se pode constatar, trata-se de uma ideia bastante semelhante àquela constante no Plnao Nacional de Educação - PNE em debate no Congresso Nacional, de remuneração equivalente para os professores aos profissionais com nível de formação equivalente. O Manifesto avança também apontando, já em 1932, para a formação universitária, questão ainda não resolvida na legislação brasileira.

6 Tal era a preocupação, que este trecho seria citado literalmente no "Manifesto dos Educadores - Mais uma vez convocados", escrito por Fernando de Azevedo, em 1959, e assinado por pioneiros e por representantes da "nova geração" de educadores. 0 documento viria a público no contexto dos debates da LDB, após a apresentação do substitutivo do Deputado Carlos Lacerda. 0 Manifesto denunciava ainda a "deficiência de recursos aplicados à educação" e reclamava das "aberturas financeiras" e do "excesso de centralização" (BARROS, 1960, p.60 e 63). 


\section{IV- Balanço preliminar}

Como se pode observar, o Manifesto consegue se posicionar e, mais do que isto, pautar as questões centrais que envolvem o financiamento da educação:

- Cabe ao Estado financiar, do que decorre o princípio da gratuidade do ensino em estabelecimentos oficiais. Tema atualíssimo e sob constante pressão, em especial na educação superior;

- Abrangência da escola única assegurada a todos dos 7 a 15 anos;

- Perspectiva da obrigatoriedade - até o final da escola secundária;

- Educação superior - para os "melhores e mais capazes" (redação próxima daquela do vigente art. 208, V, da Constituição Federal), gratuita nos estabelecimentos oficiais e baseada no tripé ensino, pesquisa e extensão, o que implica em gastos consideráveis;

- Responsabilidade pela oferta educacional cabendo basicamente à esfera estadual; União cuida do ensino na capital e exerce ação supletiva e de fiscalização. Este princípio, que remonta ao ato adicional de 1834, sofreu forte modificação com a política de fundos (Fundef e Fundeb).

- Magistério - formado preferencialmente em nível superior universitário e com remuneração equivalente ao professor que atua no nível superior. Hoje com base em dados da PNAD significa dobrar o salário;

- No manifesto fica clara a necessidade de um PNE. O documento critica a falta de visão global de reformas anteriores e propõe um plano integral.

Pouco depois do Manifesto, conforme registra Melchior (1975), foi tomada a primeira medida de ordem prática no período republicano: a instituição de taxa de educação e saúde, com o objetivo de constituir o fundo especial para a Educação e Saúde (Decreto n²1.335/32)

\section{V- Para além do Manifesto: Os impactos na legislação e o aprofundamento das propostas de financiamento por Anísio Teixeira}

Nos anos subsequentes ao manifesto, as ideias referentes ao financiamento foram defendidas e aprofundadas por Anísio Teixeira. Já no primeiro momento articularam-se os principais agentes - governo, pioneiros e católicos - todos preparando seus anteprojetos para a assembléia constituinte.

Do lado governamental, o anteprojeto de Constituição, elaborado em 1933 pela Comissão nomeada pelo chefe do governo provisório, Getúlio Vargas, não previa a vinculação de recursos nos dispositivos referentes à Educação (art.111 e seguintes), mas estabelecia a possibilidade de intervenção da União (art.13, "e") para "tornar efetiva a aplicação mínima de 10\% dos impostos estaduais e municipais no serviço de instrução primária e 10\% na saúde pública". Note-se que, no texto final, em relação ao anteprojeto a abrangência foi estendida do ensino primário para os sistemas de ensino, sem distinção de etapas de ensino, e o percentual foi elevado, no caso dos Estados, de 10\% para 20\%. Esta elevação respondeu a crítica da Associação Brasileira de Educação (1934, p.48) que ressaltava que a percentagem média que os estados brasileiros despendiam com instrução pública correspondia a $15,6 \%$ das suas rendas. Assim, o mínimo fixado no anteprojeto seria um retrocesso.

Este anteprojeto precedeu a elaboração da Constituição de 1934, que finalmente incorporou em seu texto a vinculação de recursos e a criação de fundos nos seguintes termos:

Art. 156. A União e os Municípios aplicarão nunca menos de dez por cento, e os Estados e o Distrito Federal nunca menos de vinte por cento, da renda resultante dos impostos, na manutenção e no desenvolvimento dos sistemas educativos. (grifo nosso)

7 Dos recursos, um terço cabia à educação e dois terços à saúde. 0 regulamento do "fundo de educação e saúde" estabelecia limitação não contida no decreto que criara a fonte: os recursos da educação seriam destinados ao ensino secundário, superior e técnico-profissional, excluído, portanto, 0 ensino primário (Decreto $\mathrm{n}^{0} 21.452 / 32$ ). Após sucessivos adiamentos (Decretos $\mathrm{n}^{0} \mathrm{~s} 21.784 / 32$ e 21.636/32), foi fixada a data de $1^{\circ}$ de janeiro de 1933 para início da cobrança da taxa. A taxa correspondia a 200 réis sobre todos e quaisquer documentos sujeitos a selo, excluída a correspondência postal. Não tardou a serem isentos os cheques (Decreto $\mathrm{n}^{0} 21.602 / 32$ ). 
Parágrafo único. Para a realização do ensino nas zonas rurais, a União reservará, no mínimo, vinte por cento das quotas destinadas à educação no respectivo orçamento anual.

Art. 157. A União, os Estados e o Distrito Federal reservarão uma parte dos seus patrimônios territoriais para a formação dos respectivos fundos de educação. (grifo nosso)

$\S 1^{\circ}$ As sobras das dotações orçamentárias, acrescidas das doações, percentagens sobre o produto de vendas de terras públicas, taxas especiais e outros recursos financeiros, constituirão, na União, nos Estados e nos Municípios, esses fundos especiais, que serão aplicados exclusivamente em obras educativas determinadas em lei.

$\S 2^{0}$ Parte dos mesmos fundos se aplicará em auxílios a alunos necessitados, mediante fornecimento gratuito de material escolar, bolsas de estudo, assistência alimentar, dentária e médica, e para vilegiaturas.

O segmento católico articulara a Liga Eleitoral Católica e passou a apoiar os candidatos à constituinte que assumissem seu programa mínimo.

Na V Conferência, já dissociados do grupo católico, os pioneiros haviam constituído a "comissão dos 10", que deveria elaborar estudo acerca das atribuições dos governos federal, estaduais e municipais, relativamente à educação. Este estudo deveria ser referendado pela "comissão dos 32", composta pelos delegados de cada estado. Anísio Teixeira presidia a "comissão dos 10" e Fernando de Azevedo a dos 32 (GHIRALDELLI, 2006). No estudo que originou o anteprojeto da ABE nota-se o "dedo" de Anísio, em relação à questão do financiamento.

A justificação do anteprojeto, assinada por Anísio Teixeira é esclarecedora, acerca de temas como o PNE, a reafirmação da doutrina federativa e o financiamento (grifos dos autores):

Depois de estudos demorados, veio a prevalecer na Comissão, a doutrina de que à União, como poder central, deveria caber a função de elaborar um plano geral de educação, para todo país, plano que obedeceria as características fixadas pela própria Constituição e teria flexibilidade e extensão necessárias para permitir o livre desenvolvimento das iniciativas regionais e locais $\mathrm{e}$ a adaptação às condições diversíssimas do meio brasileiro

[...] Resta examinar o ponto de vista em que se colocaram os autores do anteprojeto entregando à União a competência, tão somente ,da fixação de um plano educacional, cuja execução deverá coordenar e estimular, exercendo uma ação supletiva, onde se fizer preciso, por deficiência de meios e de iniciativas.

Transferiu-se da União para os estados, a competência de organizar, administrar e custear os sistemas educacionais.

[...] A uniformização federal do ensino viria retirar, fatalmente, a vitalidade às instituições educativas que vegetariam, por aí, sob a compressão uniformizante e longínqua do poder federal. Por último, mas nem por isso argumento de menor força, impressionou à comissão a necessidade de variedade para que se permitisse a livre experimentação e a vitória do melhor,pelo seu próprio mérito e não por imposição legal.

Esses argumentos e vários outros ainda, levaram-nos à conclusão de que se tornava indispensável dar aos Estados completa autonomia na organização e administração dos sistemas educacionais locais.

[...] A tendência de descentralização administrativa não chegou, entretanto, a levar a comissão a entregar aos municípios a direção dos seus sistemas locais de ensino. Razões provenientes de nossa evolução histórica, do ensino embrionário da maioria dos municípios brasileiros, como ainda da necessidade de orientação especializada e técnica dos sistemas educacionais, militaram a favor da centralização parcial dos sistemas educacionais nos Estados.

[...] Complemento dessa autonomia administrativa e técnica, é a autonomia financeira que ficou assegurada, no anteprojeto, pela constituição dos fundos de educação.

São eles nacional e estaduais e se organizam por meio de impostos especiais e percentagens sobre as rendas da União, dos Estados e dos Municípios. A medida é de tal importância que se justifica por si mesma. Sem ela, tudo mais não será senão palavra inútil, cuja execução se não poderá garantir.

Assim, na proposição da $A B E$, os fundos se organizariam por meio das vinculações.

Os pioneiros da Escola Nova obtiveram algumas vitórias no texto constitucional. Em primeiro lugar, a Constituição de 1934 previa a educação como direito de todos (art.149), mas as expressões "direito" e "direito de todos" desapareceriam do texto da Carta do Estado Novo (1937). Em relação, especificamente, ao 
financiamento da Educação, foram estabelecidas a vinculação de recursos à manutenção e desenvolvimento dos sistemas educativos (art. 156), a ação supletiva da União, onde se fizesse necessária, por deficiência de iniciativa ou de recursos ( art. 150, "e") e a criação de fundos por esfera da Federação, para cuja formação a União, os Estados e o Distrito Federal deveriam reservar uma parte dos seus patrimônios territoriais (art. 157), mas que foram constituídos, na prática, por sobras orçamentárias. Introduzia-se, pois, a política de vinculação, mas com a adoção paralela dos fundos - a primeira alimentada por impostos, os segundos por patrimônios territoriais. Ambos previstos em dispositivos distintos da Constituição. A redação do texto constitucional, embora representasse uma vitória dos Pioneiros, dissociava a vinculação dos impostos dos fundos, itens que apareciam associados na formulação original da ABE, que entre suas aspirações, tais como formuladas por seu Conselho Diretor, reivindicava:

$\S 5^{0}$ - 0 fundo de educação nacional será constituído de uma percentagem não inferior a 10\% da renda dos impostos da União, de impostos e taxas especiais e outros recursos financeiros eventuais.

A mesma proposição (com diferente percentual - 20\%) era feita para os Estados e para o Distrito Federal (ABE, 1934, p.35).

A adoção de fundos como forma de organização dos recursos vinculados somente seria retomada com o Fundef e, posteriormente, com o Fundeb.

No período entre o fim da República Velha a o advento do Estado Novo, o debate educacional foi marcado por uma efervescência incomum. No aspecto das relações entre federalismo e educação, surge a ideia proclamada pelo chefe do governo, do espírito de cooperação. O Manifesto dos Pioneiros deixa clara sua adesão à doutrina federativa. O programa da Escola Nova é parcialmente vitorioso ao obter a consagração na Constituição de 1934, da criação de fundos e da vinculação de recursos, embora dissociados. A educação é reconhecida como direito de todos.

Outro indicador de que Anísio Teixeira foi o principal inspirador do trecho que trata explicitamente do financiamento da educação no Manifesto, pode ser observado na seguinte declaração sua, de 1935, constante no livro Educação para a Democracia:

Precisamos - e por aí é que se há de inferir a sinceridade pública dos homens brasileiros - constituir fundos para a instrução pública, que estejam não só ao abrigo das contingências orçamentárias normais, como também que permitam acréscimos sucessivos, independentemente das oscilações de critério político de nossos administradores (TEIXEIRA, 1997, p.230).

Para aprofundar um pouco a visão deste educador, vamos nos basear no texto "Sobre o problema de como financiar a educação do povo brasileiro: bases para a discussão do financiamento dos sistemas públicos de educação", publicado originalmente na Revista Brasileira de Estudos Pedagógicos, v. 20, n. 52, out./dez/ 1953. Para tanto, adotamos a segunda edição do mesmo texto publicada no mesmo periódico, v.80, n. 194, p. 103113, jan./abr. 1999. Ao que tudo indica, resultou de uma apresentação sua feita ao Congresso Nacional.

Na ocasião, o autor ressaltou que nos "países civilizados" há dois processos para se financiar a educação: a fixação de impostos privativos, e ele cita os EUA como exemplo, e o de vinculação de uma porcentagem da renda tributária, que o foi aquele adotado pela Constituição Federal de 1946. Como vimos, esta carta constitucional determinou que "10\% da tributação federal, $20 \%$ da estadual e $20 \%$ da municipal sejam aplicados na educação". Anísio Teixeira salienta o avanço da vinculação, mas ressalta a necessidade de um "fundamentado plano" que otimize a aplicação dos recursos e que coordene os empreendimentos educacionais e "não se tripliquem, com desperdício de dinheiro e outros lamentáveis desperdícios."

Sua proposta é que se constitua um "anteprojeto formal de plano concreto ou definitivo, para convênios entre os vários poderes públicos entre si”. Este plano deve assegurar, entre outros os seguintes aspectos:

"A manutenção de um sistema de escolas públicas e gratuitas para toda a população, que ofereça o mínimo de educação reputado necessário para a vida normal do Brasileiro (...), mínimo este "condicionado pelo desenvolvimento brasileiro e pelos recursos disponíveis da nação". Como se pode observar, trata-se de um 
antecedente da proposta do CAQi (Custo Aluno-Qualidade inicial) desenvolvida pela Campanha Nacional pelo Direito à Educação e aprovada pelo Conselho Nacional de Educação, embora ainda não homologada.

- Uma escola primária de cinco anos para toda a população urbana e para a população rural, "uma modalidade quiçá e provisoriamente menos longa".

- Dada a dimensão dos desafios, "trata-se (...) de empresa que não pode ser atacada globalmente, mas pela unidade local (na órbita do município), em torno dela conjugando-se os demais esforços estaduais e federais". Trata-se de algo muito próximo dos Distritos Escolares dos EUA, que o autor deve ter conhecido de perto em sua permanência no país;

- Necessidade de dobrar os recursos aplicados, mas, ao que tudo indica, apenas pela otimização dos recursos vinculados;

- Os recursos municipais disponíveis por aluno serviriam de "soalho", aos quais se acrescentariam recursos estaduais e federais com vistas a melhorar a qualidade do atendimento;

- Seriam constituídos fundos a partir do total dos recursos vinculados: um fundo federal com os $10 \%$ vinculados e respectivos fundos estaduais e municipais com os respectivos percentuais de vinculação;

- Estes fundos seriam administrados por órgãos autônomos, os Conselhos, que seriam "precipuamente, conselhos de administração dos fundos de educação, cabendo-Ihes funções "semi-legislativas", como a de aprovar os orçamentos e planos de trabalho e a de nomear os chefes dos respectivos órgãos executivos, com exceção do federal, em que o ministro de Estado seria o presidente do Conselho, com os poderes de propor ou nomear diretores dos órgãos de estudo e execução" (p. 110). Como se vê, a democracia fica mais para o âmbito dos estados e municípios. Insistimos: o modelo proposto pelo autor é muito similar ao que existia e existe até hoje nos EUA. A diferença é que hoje o papel dos governos estaduais e do governo federal no financiamento é muito maior o que gera, como contrapartida, uma maior cobrança de resultados, geralmente na forma de desempenho dos alunos e que tem gerado toda a polêmica do uso intensivo de testes padronizados e de formas de 'responsabilização' pelos resultados que agora chega ao Brasil.

- O ponto de partida do modelo é o ensino primário obrigatório para crianças de 6 a 12 anos que deveria servir de base para todos os cálculos;

- O valor do fundo municipal dividido pelo total de alunos nesta faixa etária constituir-se-ia no 'soalho'. A "quota-auxílio" do Estado, por aluno, seria um acréscimo ao orçamento municipal, que iria permitir um melhoramento proporcional de cada item do orçamento municipal;

- Curiosamente, o fato de haver diferenças na riqueza entre os municípios é visto como elemento positivo "pois umas custariam menos que as outras (...) e o Estado, por sua vez, não constituiria outro sistema escolar mais caro e paralelo ao municipal” (p. 109);

- Os recursos do fundo seriam divididos em recursos para custeio e investimentos, abrindo-se inclusive a possibilidade de "empréstimos escolares" o que permitiria ampliar "as possibilidades de inversão e constituição dos seus patrimônios de prédios e equipamentos";

- As escolas "secundárias" (que na época incluíam os atuais anos finais do ensino fundamental e o ensino médio) também ficariam com os municípios, "e as superiores, sempre com uma larga autonomia, ficariam a cargo dos Estados e da União";

- O ensino particular, "sempre que organizado com o espírito de cooperar com o poder público, isto é, em empreendimentos sem intuito de lucro e com estatutos que não discriminem sua clientela de alunos, seria considerado parte do sistema público de ensino" e poderia receber "bolsas para os alunos desprovidos de recursos".

8 Para mais informações sobre este sistema de financiamento ver Pinto (2005). 
O autor conclui, citando a frase de Euclides da Cunha que afirmava que nossa alternativa era "progredir ou perecer" que, "hoje, nossa alternativa é 'progredir e perecer' ou 'progredir e. não perecer', o que só conseguiremos se nos dispusermos a preparar e planejar as etapas sucessivas de nosso progresso espontâneo e acelerado. Do contrário o próprio progresso, desordenado e anárquico, nos fará submergir nos caos".

Como vemos, neste texto, Anísio Teixeira que, em nosso entendimento, foi o responsável pela introdução por Fernando de Azevedo da noção de fundos para o financiamento da educação no Manifesto, no texto aqui discutido, avança no detalhamento da proposta que, em última análise, seria uma interessante combinação entre o sistema de vinculação de impostos para a educação e o modelo de gestão dos recursos educacionais adotado, em linhas gerais, ainda hoje pelos EUA.

Em nosso entendimento o modelo proposto, embora ainda tenha suas incongruências ( $\mathrm{O}$ que seria um "soalho" de qualidade? Como o ensino pós-primário seria financiado?) é uma solução mais orgânica do que atual política de fundos que, embora crie fundos únicos estaduais, mantém a existências de redes estaduais e municipais, com claros problemas de otimização de recursos e de formas de colaboração. Os conselhos propostos por Anísio Teixeira, em clara referência aos "School Board" que comandam os distritos escolares nos EUA, representam também um significativo avanço em relação aos Conselhos de Acompanhamento e Controle Social do Fundeb, os quais são desprovidos do poder de aprovar o orçamento educacional ou deliberar sobre a execução dos recursos, além de não disporem de estrutura própria e independente das secretarias de educação para fiscalizar a aplicação dos recursos. Nesse sentido, não passam de uma pálida sombra do modelo proposto por Anísio Teixeira.

Concluímos este trabalho ressaltando a atualidade do Manifesto e o vigor das propostas ali delineadas, particularmente no que se refere ao financiamento da educação. Ressaltamos também a importância de, em um momento em que a nação discute a aprovação de mais um Plano Nacional de Educação, assegurar instrumentos institucionais para que o planejamento estatal que se configura nos planos plurianuais, nas leis de diretrizes orçamentárias e nas leis orçamentárias deixem de ser documentos meramente decorativos e se transformem em instrumentos que orientem as mudanças tão necessárias para o país. 


\section{Referências Bibliográficas}

ABE. O problema educacional e a nova Constituição. São Paulo: Companhia Editora Nacional, 1934.

AZEVEDO, F. A educação entre dois mundos. São Paulo: Melhoramentos, 1958.

A reconstrução educacional no Brasil. Ao povo e ao governo. O manifesto dos pioneiros da educação nova. São Paulo: Ed. Nacional, 1932.

CARVALHO, M. M. C. O território do consenso e a demarcação do perigo: política e memória do debate educacional dos anos 30. In: FREITAS, M. C. (Org.) Memória intelectual da educação brasileira. Bragança Paulista-SP: Editora da Universidade São Francisco-EDUSF, 1999.

CUNHA, C. Educação e autoritarismo no Estado Novo.São Paulo: Cortez/Autores Associados, 1981.

CUNHA, N. A revolução e a educação. Brasília: Plano; Autores Associados, 2003.

FAUSTO, B. História do Brasil. São Paulo: Editora Universidade de São Paulo, 1994.

FREITAS, M. C. Educação brasileira: dilemas republicanos nas entrelinhas de seus manifestos. In: STEPHANOU, Maria e BASTOS, Maria Helena Camara. História e Memórias da educação no Brasil, vol. III séc. XX. Petrópolis: Editora Vozes, 2005.

GHIRALDELLI JR, P. História da Educação Brasileira. São Paulo: Cortez Editora, 2006.

MARTINS, P. S. Fundeb, federalismo e regime de colaboração. Campinas-SP: Autores Associados, 2011.

MELCHIOR, J. C. A. Financiamento da educação no Brasil: recursos financeiros públicos e privados.

[S.I.]: ANPAE, 1975. (Cadernos de Administração Escolar, VI). Tese apresentada à Faculdade de Educação da USP, em 1972.

NAGLE, J. Educação e Sociedade na primeira República. São Paulo: E.P.U; USP, 1974.

NUNES, C. O Estado Novo e o debate educacional nos anos trinta. In: Freitas, Marcos Cezar (Org.) Memória intelectual da educação brasileira. Bragança Paulista-SP: Editora da Universidade São Francisco-EDUSF, 1999.

PAGNI, P. A. Do manifesto de 1932 à construção de um saber pedagógico. Ensaiando um diálogo entre Fernando de Azevedo e Anísio Teixeira. IJUÍ, RGS, Ed. UNIJUÍ, 2000.

PINTO, J. M. R. Os recursos para Educação no Brasil no contexto das finanças públicas. Brasília: Editora Plano, 2000.

PINTO, J. M. R. Uma análise do financiamento da educação no Estado da Califórnia, EUA. Cadernos de Pesquisa. São Paulo, v.35, n.126, p.699-722, set./dez. 2005.

ROMANELLI, O. O. História da Educação no Brasil. 28 edição. Petrópolis: Editora Vozes, 2003.

SAVIANI, D. História das Idéias Pedagógicas no Brasil. Campinas-SP: Autores Associados, 2007.

TEIXEIRA, A. Educação para a democracia. Rio de Janeiro: Editora UFRJ, 1997.

VIANA FILHO, L. Anísio Teixeira: a polêmica da educação. Rio de Janeiro: Nova Fronteira, 1990.

VIDAL, D. G. (Org.) Na Batalha da educação: Correspondência entre Anísio Teixeira e Fernando d e Azevedo (1929-1971). Bragança Paulista: EDUSF, 2000.

XAVIER, L. N. Para além do campo educacional: um estudo sobre o manifesto dos pioneiros da educação nova (1932). Bragança Paulista-SP: Editora da Universidade São Francisco-EDUSF, 2002.

Recebido em Dezembro de 2013 Aprovado em Dezembro de 2013 